\title{
CONE BEAM COMPUTED TOMOGRAPHY (CBCT) IN GENDER DETERMINATION THROUGH MENTAL FORAMEN POSITION IN AN EGYPTIAN POPULATION SAMPLE (A RETROSPECTIVE STUDY)
}

\author{
Esraa A. Elmekkawy ${ }^{1 *}$ BDS, Yousria S. Gaweesh ${ }^{2}$ Phd, Rania A. Fahmy ${ }^{3}$ Phd, Wael M. \\ Safwat ${ }^{4}$ Phd \\ ABSTRACT
}

BACKGROUND: Identification and determination of gender of unknown human skeletal remains has been one of the most challenging tasks for forensic dentistry.

AIM OF THE STUDY: The purpose of this study is to assess the role of cone beam computed tomography (CBCT) in gender determination through the measurements of the location of the mental foramen in in a sample of the Egyptian population.

MATERIALS AND METHODS: Two measurements were performed in 200 CBCT images 2 measurements were performed; distance from the upper border of mental foramen to the lower border of the mandible and distance from the lower border of mental foramen to the lower border of the mandible in the right side of each CBCT image. Obtained data were statistically analyzed using t-test to compare between the two genders.

RESULTS: The two measurements were significantly higher in males.

KEYWORDS: CBCT, gender determination, linear measurements ,mental foramen.

1 Instructor at Periodontology, Oral Medicine \& Oral radiology department, faculty of dentistry, Alexandria university.

2 Professor at Periodontology, Oral Medicine \& Oral radiology department, faculty of dentistry, Alexandria university.

3 Lecturer at at Periodontology, Oral Medicine \& Oral radiology department, faculty of dentistry, Alexandria university.

4 Assistant Professor at Oral radiology department, faculty of dentistry ,Mansoura university.

* Corresponding author:

Email: esraa.dentist2012@gmail.com

\section{INTRODUCTION}

Forensic anthropology is the application of the science of physical or biological anthropology to the legal process. The identification of human skeletal remains is considered an initial step in forensic investigations and is crucial for further analysis. $(1,2)$

In the adult skeleton, sex determination is usually the first step of the identification process. Subsequent methods for age and stature estimation are sex dependent. The reliability of sex determination depends on the completeness of the remains and a degree of sexual dimorphism inherent in a population(2,3).

The use of data from a specific population is important because sexual dimorphism varies among different populations. Sexual dimorphism is a method that has been used for many years within forensic dentistry for human identification. This method is better in adults because of the morphological influences that affect bone structure such as the hormones that control growth, bone change and developments during puberty(4).
When the entire adult skeleton is available for analysis, sex can be determined up to $100 \%$ accuracy, but in cases of mass disasters where usually fragmented bones are found, sex determination with $100 \%$ accuracy is not possible and it depends largely on the available parts of skeleton(1-3).

As evident from earlier studies, The skull is the most dimorphic and easily sexed portion of skeleton after pelvis, providing accuracy up to $92 \%(1)$. But in cases where intact skull is not found, the mandible may play a vital role in sex determination as it is the most dimorphic, largest, and strongest bone of the skull $(1,5)$. The mandible is the strongest bone in the human body and persists in a well-preserved state longer than any other bone. Therefore, the use of morphological features of the mandible is a common approach used by anthropologists and forensic dentists in the determination of gender(6).

Previous studies have indicated that the relative position of the mental foramen in adults can be used to estimate sexual dimorphism and age $(4,7)$.

Arguably, these differences can be used as proposed values for forensic identification of human remains . Some studies have attempted to determine the influence of age and sex on the relative position of the 
mental foramen on cone beam computed tomography (CBCT) images. In general, the results have demonstrated that the relative location of the foramen in adults remains fairly constant with increasing age or sex, although some studies have shown different results(4, 7). New research results using different populations and with larger samples are needed to evaluate the relative position of the mental foramen to provide sex determination in a specific population(4).

Radiographs are indispensable tools that are used in forensic anthropology. The radiographic method is the simplest and cheapest method for age estimation and gender determination when compared to the histological and biochemical methods. The accuracy of measurements on radiographs is based on the quality of the radiographs(8).

In forensic medicine, numerous studies have used computed tomography (CT) as an auxiliary method in the discovery of unidentified bodies post-mortem. A study used CT to estimate the age of human bodies using the third molar tooth, the medial epiphysis of the clavicle and sphenooccipital synchondrosis in a sample of Australian individuals(9). CT imaging technique generates multiple high quality images enabling three dimensional (3D) visualization and complete osseous anatomical information $(10,11)$.

Cone beam computed tomography (CBCT) is a relatively new $\mathrm{CT}$ system designed to focus on the head and neck region; an X-ray beam and detector system move around the part of the body being examined. CBCT is the preferred method for diagnosis in almost all fields of dentistry including endodontics, orthodontics, periodontics, maxillofacial surgery and forensic dentistry.(12) CBCT is a more compact and cost-effective method when compared with systems based on multidetector computed tomography (MDCT) and loses none of the reliability and accuracy of the MDCT images (13-15).

Interest in anatomical features and anatomical variations in the human mandible has increased in recent years due to the widespread use of $\operatorname{CBCT}(13,16)$. CBCT provides 3D evaluation of mandible, and its measurement accuracy is superior to panoramic radiography(17). CBCT is highly accurate and reproducible in linear measurements in the axial and coronal image planes and in different areas of the maxillofacial region (18).

Therefore, the aim of this study was to evaluate the role of CBCT in gender determination through measuring the location of the mental foramen in a sample of Egyptian population.

\section{MATERIALS AND METHODS \\ Study design}

A retrospective study was conducted on two hundred CBCT radiographs. The study was accepted by the Research Ethics Committee of the faculty of Dentistry, Alexandria University (IRB NO: 00010556IORG0008839). No informed consent was needed as every CBCT was taken as anonymous.

Criteria for patient selection

\section{Inclusion Criteria}

1. CBCT images already taken for implant, endodontic or root fracture treatment .

2. Subjects above 18 years of age and below 60 years.

3. Subjects with no oral-maxillofacial surgical intervention manifested in the radiographs

4. Radiographic images free of artifacts in the site of measurements.

\section{Exclusion Criteria}

1. Less than 18 years of age because of invisibility of mental foramen due to mixed dentition.

2. Distortion of images.

3. Presence of artifacts

4. Presence of fractures or pathological lesions in the mandible at the site of measurements.

\section{A) Data collection}

Two hundreds CBCT images (100 males and 100 females ) of patients aged between 18 and 60 years have been collected randomly from the Oral Radiology Centre of Faculty of Dentistry, Alexandria university.

\section{B) Images analysis}

CBCT scans were performed using the high-resolution imaging system; CAT Next Generation (Imaging Sciences International, Hatfield, Pa) CBCT unit in Faculty of Dentistry, Alexandria university A standardized protocol of the i-CAT was used for all patients using the same machine with the following exposure parameters: 120 Kvp, $5 \mathrm{~mA}$, with $16 \times 8 \mathrm{~cm}$ for the mandible FOV and 26.9 seconds at 0.25 resolution.

Data from CBCT scans was exported in Digital Imaging and Communications in Medicine (DICOM) format into the OnDemand $3 \mathrm{D}^{\mathrm{TM}}$ software by Cybermed Inc. to reconstruct $3 \mathrm{D}$ volumes.

All the measurements were performed using the same screen. Measurements were made to the nearest $0.1 \mathrm{~mm}$ using the software tools including: linear measurement tool and a digital magnification lens.

C) Tomographic measurements

Two measurements were taken for the mental foramen of the right side from a coronal slice; (fig 1)

- For standardization the view should show the mental foramen at its maximum opening

- In the axial view the sagittal plane should be perpendicular on the long axis of the mandibular

- The coronal view window was maximized

- The lens was used to zoom in till the side ruler reached 1 $\mathrm{cm}$

- The ruler was used to measure

1. Superior Mental Foramen (SMeF): The distance from the superior end of mental foramen to the midpoint of the lower border of the mandible at the point of maximum curvature.

2. Inferior Mental Foramen (IMeF): The distance from the inferior end of mental foramen to the midpoint of the lower border of the mandible at the point of maximum curvature:

\section{Statistical analysis}

The two measurements obtained were compared between the genders and student t-test was used to assess the 
difference between them. The data was analyzed using IBM SPSS statistical software (version 25).

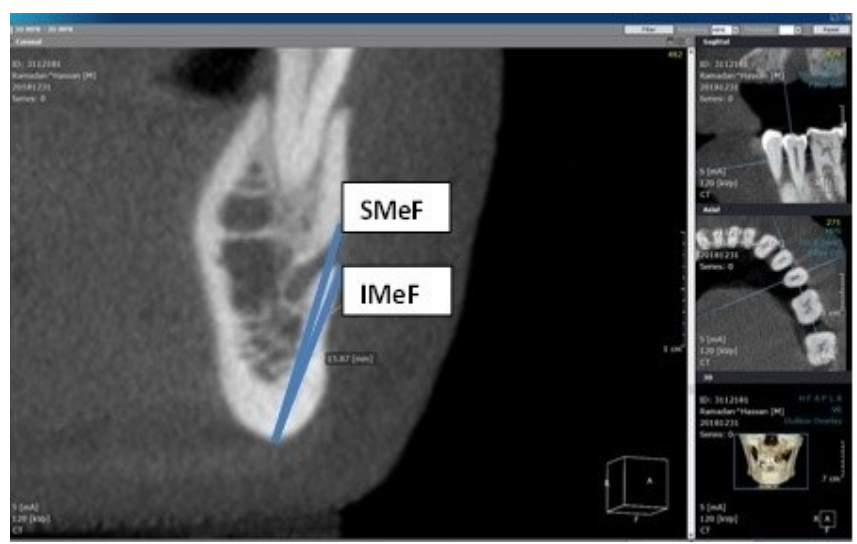

Figure 1: $\mathrm{SMeF} \& \mathrm{IMeF}$ measurements on the coronal cut of a CBCT radiograph

\section{RESULTS}

Table (1):

Table (1) presents the data (in millimeters) obtained from the comparison of $\mathrm{SMeF}$ measurement between males and females in the right side .

The results of the right side of the males showed a minimum value of 11.5 and a maxinum value of 21.5 . The mean and the standard deviation were 16.69 and 1.98 respectively with a median 17 .

The right side of the females had a minimum and a maximum values equal to 12.9 and 20 respectively. The mean, standard deviation and the median were $15.8,1.5$ and 15.7 respectively.

This table shows that the SMef mean the right of the males was significantly higher than that of females $(\mathrm{P}=0.001)$.

Table 1: Comparison of SMeF (in mm) between males and females

\begin{tabular}{|c|c|c|c|}
\hline SMeF & Males & Females & $\mathbf{P}$ \\
\hline Right & $(n=93)$ & $(\mathrm{n}=\mathbf{8 0})$ & \\
\hline $\begin{array}{l}\text { Min. } \quad- \\
\text { Max. }\end{array}$ & $\begin{array}{l}11.50- \\
21.50\end{array}$ & $\begin{array}{l}12.90 \\
20.0\end{array}$ & \\
\hline $\begin{array}{l}\text { Mean } \quad \pm \\
\text { SD. }\end{array}$ & $\begin{array}{l}16.69 \pm \\
1.98\end{array}$ & $\begin{array}{l}15.82 \\
1.50\end{array}$ & $0.001^{*}$ \\
\hline Median & 17.0 & 15.70 & \\
\hline
\end{tabular}

Table (2):

Table (2) presents the data (in millimeters) obtained from the comparison of IMeF measurement of the right side between males and females

The results of the right side of the males show that minimum value was 9.3 and the maximum one was 16.8 . The mean and the standard deviation of the values were 13.32 and 1.77 respectively. The median was 13.3.
The right side of the females had a minimum and a maximum values equal to $10.1,15.9$ respectively. The mean, standard deviation and the median were 12.48, 1.5 and 12.1 respectively

This table shows that the IMef mean of the right side of the males was significantly higher than that of females $(\mathrm{P}=0.001)$.

Table 2: Comparison of IMeF (in $\mathrm{mm}$ ) between males and females

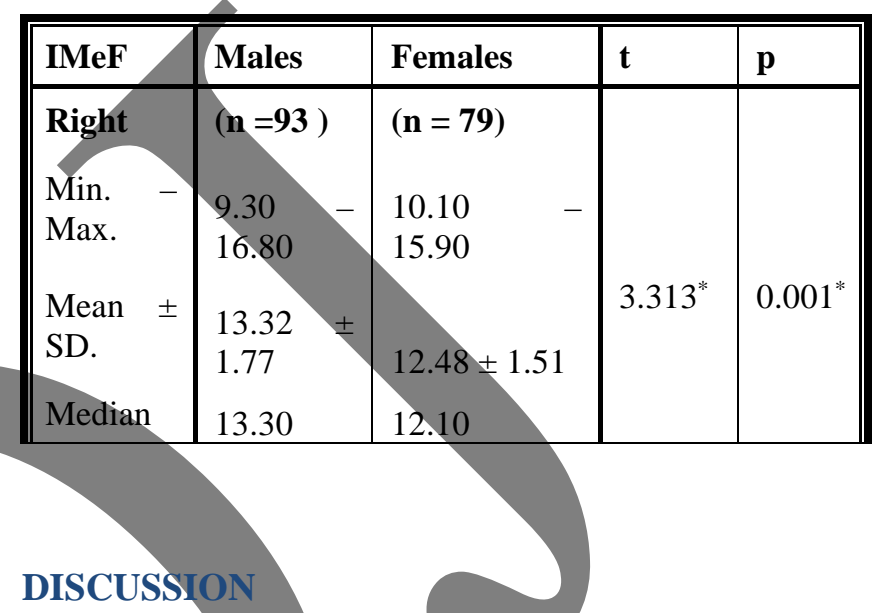

Forensic dentistry has been using various techniques, like those used by dental practitioner, in the human identification process. The estimation of race, sex, age and stature in the living or dead is a main step of any legal investigation. Sex determination is considered a cornerstone in forensic medicine as it primarily halves the possibilities of the remains $(19,20)$.

Sex determination is to classify an individual as either male or female. To reach an allocation of sex, specialist use biological traits that differ between the two sexes. Despite there are only two biological sexes present in humans, sex determination of a human skeleton is still a challenge(21).

Various studies have been done to differentiate between the genders of unknown individuals (22-24). The specific characteristics for each population have to be studied, as there is a diversity in the morphometric characteristics among various populations all over the world.

The mandible is used for sexual dimorphism as it is significantly available and can resist many disintegration processes. However, levels of sexual dimorphism are population specific due to a combination of genetic and environmental factors(25).

Among many anatomical landmarks in human skull, the mental foramen is a stable landmark on the mandible. Because of the stability of the basal bone and mental foramen, these landmarks were selected as a point of reference for the present study(26).

CBCT has made a great revolution in dentistry, in diagnosis and planning(27), with minimal radiation dose and artifacts(28-30). CBCT tri-dimensional images offer accurate measurements for clinical application(31). 
When comparing CBCT with MDCT we can find that CBCT is related to much less metal artifacts and as a result it is reliable in localization of metallic foreign objects. Therefore, we can claim that beside accuracy and reliability, CBCT offers higher image quality when metallic objects are present(25).

In our study we used CBCT as a tool for sexual determination through the position of mental foramen of the right side .We measured the distance from the superior and inferior borders of the foramen to the lower border of the mandible $(\mathrm{SMeF})$ and $(\mathrm{IMeF})$.

Our study results revealed that the mean of SMeF and IMeF of the right side is significantly higher in males. This may be attributed to the difference in the speed of growth of the bone between genders. The speed of growth is higher in males by 5 to $9 \%$ in comparison with women. Moreover, the muscular tension is the inductive component of bone growth. Generally, men possess stronger masticatory muscles when compared with females (32).

Our results were similar to that of an Indian study that proved that the two measurements were higher in males. In an American study of cadaveric heads, Cutright et al,(33). reported that the position of the mental foramen showed a small but significant difference between men and women.

Our study results were in contrast with Uppal Study that was conducted on an Indian population aimed at evaluating the role of mental foramen and mandibular canal in gender determination using CBCT. In the later study, no significant difference was noted with regard to the $\operatorname{IMeF}(32)$.

This is in contrast to many studies conducted in Taiwan (34) and Thailand (35) that found that both SMeF and $\mathrm{IMeF}$ were significantly higher in males.

This variation among the populations could be due to difference in foods, habits and genetic factors resulting in distinct anatomic features. Furthermore, differences in the imaging modalities utilized in studies may also contribute to this variation as most of the previous studies have been conducted on cadavers and panoramic images(36).

\section{CONCLUSIONS}

Based on the results of this study, it is possible to conclude that the distances from the superior and inferior borders of mental foramen of the right side to the lower border of the mandible exhibited sexual dimorphism in the studied sample of the Egyptian population.

CBCT radiography is efficient for making the proposed measurements and can be considered as a method to determine gender from the skeletal remains. The technique is particularly important in mass disaster events, in which the jaws are available in fragments.

Larger study groups and comprehensive assessment of other parameters related to the mental foramen are required to confirm the results.

Conflict of interest:

The authors declare that they have no conflicts of interest

\section{REFERENCES}

1. Saini V, Srivastava R, Rai RK, Shamal SN, Singh TB, Tripathi SK. Mandibular ramus: an indicator for sex in fragmentary mandible. J forensic sci. 2011;56.

2. Indira AP, Markande A, David MP. Mandibular ramus: An indicator for sex determination-A digital radiographic study. J forensic dent sci. 2012;4:58.

3. Scheuer L. Application of osteology to forensic medicine. Clinical Anat. 2002;15:297-312.

4. Gamba TdO, Alves MC, Haiter-Neto F. Analysis of sexual dimorphism by locating the mandibular canal in images of cone-beam computed tomography. J Forensic Rad and Imag. 2014;2:72-6.

5. Hu KS, Koh KS, Han SH, Shin KJ, Kim HJ. Sex determination using nonmetric characteristics of the mandible in Koreans. J forensic sci. 2006;51:1376-82.

6. Singal K, Sharma S. Gender Determination by Mental Foramen Using Linear Measurements on Radiographs: A Study in Haryana Population. Indian J Forensic Med \& Tox. 2016;10:44-9.

Angel JS, Mincer HH, Chaudhry J, Scarbecz M. Cone-beam Computed Tomography for Analyzing Variations in Inferior Alveolar Canal Location in Adults in Relation to Age and Sex*. J Forensic Sci. 2011;56:216-9.

8. Malik M, Laller S, Saini RS, Mishra RK, Hora I, Dahiya N. Mental foramen: An Indicator for Gender Determination-A Radiographic Study.J Health Sci.2013;2:12-4.

9. Bassed RB, Briggs C, Drummer OH. Age estimation using CT imaging of the third molar tooth, the medial clavicular epiphysis, and the spheno-occipital synchondrosis: a multifactorial approach. Forensic sci int. 2011;212:273. e1-. e5.

10. O’Donnell C, Iino M, Mansharan K, Leditscke J, Woodford N. Contribution of postmortem multidetector CT scanning to identification of the deceased in a mass disaster: Experience gained from the 2009 Victorian bushfires. Forensic Sci Internat. 2011;205:15-28.

11. Oliveira-Santos C, Souza PHC, De Azambuja BertiCouto S, Stinkens L, Moyaert K, Van Assche N, et al. Characterisation of additional mental foramina through cone beam computed tomography. J Oral Rehab. 2011;38:595-600.

12. Miracle A, Mukherji S. Conebeam CT of the head and neck, part 2: clinical applications. American j neurorad. 2009;30:1285-92.

13. Mowafey B, Van de Casteele E, Youssef J, Zaher A, Omar H, Politis C, et al. Can mandibular lingual canals be used as a forensic fingerprint? J forensic odonto-stomat.. 2014;2:26-35.

14. Marmulla R, Wörtche R, Mühling J, Hassfeld S. Geometric accuracy of the NewTom 9000 Cone Beam CT. Dentomaxillofac. Rad. 2005;34:28-31.

15. Biwasaka H, Aoki Y, Tanijiri T, Sato K, Fujita S, Yoshioka K, et al. Analyses of sexual dimorphism of 
contemporary Japanese using reconstructed threedimensional CT images. Leg Med.2009;11:S260-S2.

16. Murlimanju B, Prakash K, Samiullah D, Prabhu LV, Pai MM, Vadgaonkar R, et al. Accessory neurovascular foramina on the lingual surface of mandible: incidence, topography, and clinical implications. Ind J Dent Res. 2012;23:433.

17. Sheikhi M, Karbasi Kheir M, Hekmatian E. ConeBeam Computed Tomography Evaluation of Mental Foramen Variations: A Preliminary Study. Radiology research and practice. 2015;2015.

18. Moshfeghi M, Amin Tavakoli M, Tavakoli Hosseini E, Tavakoli Hosseini A, Tavakoli Hosseini I. Analysis of linear measurement accuracy obtained by cone beam computed tomography Dent res J. 2013;1:57-62.

19. Kanchan T, Krishan K, Sharma A, Menezes RG. A study of correlation of hand and foot dimensions for personal identification in mass disasters. Forensic sci intern. 2010 2010/06;199:112.e1-.e6.

20. Krishan K, Kanchan T, Sharma A. Sex Determination from Hand and Foot Dimensions in a North Indian Population. J Forensic Sci. 2011 2011/01/31;56:453-9.

21. Rösing FW, Graw M, Marré B, Ritz-Timme S, Rothschild MA, Rötzscher K, et al. Recommendations for the forensic diagnosis of sex and age from skeletons. HOMO. 2007 2007/03;58:75-89.

22. El Morsi DA, Al Hawary AA. Sex determination by the length of metacarpals and phalanges: X-ray study on Egyptian population. J Forensic and Leg Med. 2013 2013/01;20:6-13.

23. Eshak GA, Zaher JF, Hasan EI, El-Azeem Ewis AA. Sex identification from fingertip features in Egyptian population. J Forensic and Leg Med. 2013 2013/01;20:46-50.

24. Kharoshah MAA, Almadani O, Ghaleb SS, Zaki MK, Fattah YAA. Sexual dimorphism of the mandible in a modern Egyptian population. J Forensic and Leg Med. 2010 2010/05;17:213-5.

25. Gamba TO, Oliveira ML, Flores IL, Cruz AD, Almeida SM, Haiter-Neto F, et al. Influence of cone-beam computed tomography image artifacts on the determination of dental arch measurements. The Angle Orthodontist. 2014 2014/03;84:274-8.

26. Chandra A, Singh A, Badni M, Jaiswal R, Agnihotri A. Determination of sex by radiographic analysis of mental foramen in North Indian population. $\mathrm{J}$ forensic dent sci. 2013;5:52.
27. De Vos W, Casselman J, Swennen GRJ. Cone-beam computerized tomography (CBCT) imaging of the oral and maxillofacial region: A systematic review of the literature. Int j oral and maxillofac surg. 2009 2009/06;38:609-25.

28. de Azevedo Vaz SL, Vasconcelos TV, Neves FS, de Freitas DQ, Haiter-Neto F. Influence of Cone-Beam Computed Tomography Enhancement Filters on Diagnosis of Simulated External Root Resorption. J endo. 2012 2012/03;38:305-8.

29. Ludlow JB, Davies-Ludlow LE, Brooks SL, Howerton WB. Dosimetry of 3 CBCT devices for oral and maxillofacial radiology: CB Mercuray, NewTom 3G and i-CAT. Dentomaxillofacial Rad. 2006 2006/07;35:219-26.

30. Tsurumachi $T$, Honda K. A new cone beam computerized tomography system for use in endodontic surgery. Int endo J. 2007 2007/03;40:224-32.

31.Lascala CA, Panella J, Marques MM. Analysis of the accuracy of linear measurements obtained by cone beam computed tomography (CBCT-NewTom). Dentomaxillofacial Rad. 2004 2004/09;33:291-4.

32. Uppal MK, Iyengar AR, Patil S, Vasudev SB, Kotni RM, Joshi RK. Radiomorphometric localization of mental foramen and mandibular canal using cone beam computed tomography as an aid to gender determination-A retrospective study. Int Healthcare Res J (IHRJ). 2018;2:115-20.

33. Cutright B, Quillopa N, Schubert W. An anthropometric analysis of the key foramina for maxillofacial surgery. $\mathrm{J}$ oral and maxillofac surg. 2003;61:354-7.

34. Lo L-J, Wong F-H, Chen Y-R. The Position of the Inferior Alveolar Nerve at the Mandibular Angle. Annals of plastic surg. 2004 2004/07;53:50-5.

35. Agthong S, Huanmanop T, Chentanez V. Anatomical variations of the supraorbital, infraorbital, and mental foramina related to gender and side. $\mathrm{J}$ oral and maxillofac surg. 2005;63:800-4.

36. de Oliveira Gamba T, Alves MC, Haiter-Neto F. Analysis of sexual dimorphism by locating the mandibular canal in images of cone-beam computed tomography. J Forensic Rad and Imag. 2014;2:72-6. 